\title{
PAUL GUGGENHEIM PRIZE
}

\section{TO BE AWARDED IN 2009}

The Paul Guggenheim Prize, amounting to Swiss francs 15,000 (9500€) will be awarded to a monograph of major importance in the field of public international law (except European law). The monograph must be of the highest quality and be the work of a young author at the beginning of his/her career. Works submitted may be in the form of published books or of manuscripts intended for publication; they may be written in English, French, German, Italian or Spanish. Works which have already been awarded a prize of a similar nature will not be considered.

Applications accompanied by a curriculum vitae, a list of publications and five copies of the work submitted must be received, no later than 1st February 2009, by: The Paul Guggenheim Foundation, The Graduate Institute of International Studies, 11A, avenue de la Paix, 1202 Geneva (Switzerland). Applicants are required to specify whether the work submitted has already been awarded a prize.

The Regulations pertaining to the Prize may be obtained at the same address. 